\title{
DE NEDERLANDSCHE REGEERING TEGENOVER DE KOLONIE SURINAME IN 1816
}

DOOR

\author{
JHR. L. C. VAN PANHUYS
}

Het in den Zesden Jaargang van de W. I. Gids op blz. 290-321 opgenomen artikel: „De Gouverneur-Generaal Willem Benjamin van Panhuys" berust hoofdzakelijk op de daarin besproken uitvoerige Memorie tot reorganisatie der Kolonie Suriname en op de naar alle waarschijnlijkheid in 1816 uit Suriname naar Nederland gezonden afschriften van het zoogenaamde Gouvernements journaal, op den inhoud dus van bescheiden van den landvoogd zelf afkomstig.

Nadat het aangehaalde artikel het licht had gezien heeft de samensteller gelegenheid gevonden om onderzoek te doen naar de brieven die de Nederlandsche Regeering, in dit geval de Directeur-Generaal van Koophandel en Koloniën, de Staatsraad Goldberg, aan den Surinaamschen Gouverneur-Generaal heeft toegezonden. Daartoe heeft hij, uit een op het Rijksarchief aanwezig register, waarin korte inhoudsopgaven voorkomen van de officieele brieven sinds 1815 door Hoofden van het Departement van Koophandel en Koloniën, of van Koloniën aan Gouverneurs van Suriname gericht, die nummers uitgezocht welke hem van belang voorkwamen om te zien hoe het gebiedsdeel, het eerste jaar na de teruggave door Engeland, is bestuurd of geregeerd geworden. De uitkomst van dat onderzoek, waarbij hij voor de rustige raadpleging en bestudeering van de stukken, - hetzij met veel dankbaarheid erkend -, de grootst mogelijke welwillendheid heeft ondervonden van de zijde van het Rijksarchief en het Ministerie van Koloniën, volgt hieronder. 
Wat heeft de Directeur-Generaal Goldberg zich voorgesteld na de teruggaaf van de Kolonie te doen? Heeft hij gedacht: Wij zenden daarheen een bijzonderen vriend van den Koning, die jaren lang in Suriname heeft doorgebracht, aan wien op grond van zijn antecedenten en van de door hem ingezonden (reeds geciteerde) memorie de bekwaamheid kan worden toegekend de Kolonie uit haar verval op te richten? Het is mogelijk, maar die waardeerende gedachte heeft dan niet belet, dat van het begin af den Gouverneur-Generaal op belangrijke punten werd voorgeschreven hoe te handelen, zelfs voor hij nog in zijne nieuwe hoedanigheid voet op den Surinaamschen bodem had gezet. Plannen maken? het was den Landvoogd toegestaan, maar hem in de gelegenheid stellen die plannen te volbrengen daatomtrent behield de Moederlandsche Regeering zich hare geheel vrije beslissing voor. Dat de Directeur-Generaal - die in een van zijn eerste brieven (v. 13 Dec. 1815, no. 3853) schrijft: „de kolonie Suriname en de verdere W. I. eilanden (was dit een slip of the pen, en bedoelde hij: de verder dan Suriname gelegen W. I. eilanden?) - er prijs op stelde zoo goed mogelijk van de toestanden in de Kolonie op de hoogte te worden gebracht, wie zou het laken ? $\left.{ }^{1}\right)$ Maar de wijze waarop de vraag werd gedaan was in hooge mate onhandig en bracht dan ook den G.G. het is reeds in het aangehaalde artikel vermeld, zie aldaar blz. 304 - tot een soort wanhoop. Verder blijkt, dat tusschen 23 Juli en 7 Augustus 1816, in antwoord op belangrijke en urgente voorstellen van den Landvoogd, niet minder dan zesmaal door den Directeur-Generaal werd te kennen gegeven, dat 's Gouverneurs gegevens niet voldoende waren (om de zaak door hem, Direct. Gen., te laten beoordeelen). De wijze waarop aan den opvolger van V. P., Mr. C. R. Vaillant, bij schrijven van 7 October 1816 werd medegedeeld, dat er nimmer sprake

\footnotetext{
1) De Engelsche Minister Lord Castlereagh sprak op 12 Juni 1814 in het Lagerhuis van de eilanden Berbice, Demerary en Essequebo, Publicatiën, zie hieronder, blz. LX. Beide hoogwaardigheidsbekleeders gaven elkander dus op dit punt niets toe.
} 
van zou mogen zijn, dat de Kolonie, op hoedanige wijze dan ook, eenige ondersteuning van het Moederland zou mogen genieten, zou wellicht v. P., ware hij in leven gebleven, na het voorafgaande tot heengaan hebben genoopt. Deze zoo straks weer te geven, hoogst belangrijke brief toont wel aan, dat Koning Willem I op de verhouding tusschen Directeur-Generaal en Gouverneur-Generaal veel invloed heeft gehad.

Het valt den onderzoeker op, dat de ministerieële brieven, hoewel de G.G. eerst op 26 Februari 1816 het bestuur over Suriname van Generaal Bonham overnam, met een brief van 16 November 1815 aanvangen. Uit een missive van 3 December 1815 blijkt, dat de naar zijn bestemming vertrekkende Gouverneur-Generaal o.a. vanuit Vlissingen, en ook toen het fregat „,de Euridice” zich nog ter hoogte van Blankenberge bevond, met den Directeur-Generaal brieven heeft gewisseld. Een brief van den D. G. aan den G.G. van 24 Nov. 1815 kon echter niet voor den 22sten Januari 1816 uit Nederland worden verzonden. Het nieuws van v. P.'s overlijden, op 17 Juli 1816, bereikte het Ministerie van Koloniën eerst dan 28sten September, zoodat na den sterfdag nog een aantal officieële brieven uit het Moederland aan den G. G. v. P. werden gezonden. Om te zien welk gevolg aan voorstellen van v. P. zijn gegeven, hebben wij ministeriëele brieven aan den waarnemenden Gouverneur, Mr. Vaillant, tot en met v. 3 Nov. 1817, no. 7814 geraadpleegd.

De eerste belangrijke brief van den D. G. Goldberg (v. 16 Nov. 1815, no. 3210) bevat een Memorie van voorziening, behelzende verscheidene onderwerpen: „nopens welker volbrenging in de Kolonie Suriname de nadere „,consideratiën van den G.G. zullen vereischt worden”. De memorie behandelt de volgende onderwerpen: 1 . Het leveren van slaven voor den openbaren dienst; 2 . Intrekking van de opgaven voor de quotisatie bij de Kassen tegen de wegloopers; den G.G. werd verzocht naar een aequivalent te zoeken en de intrekking mogelijk te maken van de belasting op winsten en inkomsten der ingezetenen 
welke (zoo schreef de Dir. Gen.) veel misnoegen heeft verwekt; 3. Militair toezicht door inspecties; 4 . Inning van belastingen, onderzoek naar de mogelijkheid om het aantal kantoren en ontvangers te verminderen; 5 . Bevredigde Boschnegers „men zij onverzoenlijk tegen de ,gerebelleerde negers van het vrijkorps", die zich nabij de Aucaner-Boschnegers hebben gevestigd.

Een brief van 24 Nov. d. a. v. (no. 3418) bevat de gewraakte duizend en één vragen om van de toestanden in Suriname op de hoogte te komen. Het schijnt, dat de steller van dien brief, de D. G. zelf dan wel, naar meer waarschijnlijk is, een van zijn ambtenaren, de vragen uit een of ander handboek voor staatkundige aardrijkskunde heeft overgeschreven. Er zijn verscheidene vragen bij, die men tot op heden niet, of nog in lang niet volledig dan wel eerst in deze eeuw, en dan nog maar naar schatting ,heeft kunnen beantwoorden. Zoo wordt geïnformeerd naar het aantal en de woonplaatsen van de Indianen; naar het getal inwoners en hunnen landaard hoewel, naar in het algemeen uit andere brieven blijkt, de G. G. voor uitgaven b.v. voor een volkstelling allerminst gelden tot zijne beschikking had - ; naar den stand van de beschaving en de opvoeding; eene beschrijving wordt verlangd van den graad van beschaving welke iedere klasse van inwoners bereikt heeft. Nopens de houtsoorten en de nuttige planten worden zeer uitvoerige vragen gedaan, waarop men, ook thans, nauwelijks of niet antwoord zou kunnen geven.

De D. G. kwam, na het antwoord van den G.G., - die zich onbekwaam had verklaard om de vragen in den eersten tijd te kunnen laten nagaan en in afwachting daarvan had verwezen naar een vroeger uit Suriname verstrekt antwoord op vraagpunten van Lord Dundas - bij schrijven van 24 Augustus 1816 (no. 5086) op de zaak terug, met de mededeeling, dat genoemde verwijzing niet voldoende was en intusschen gaarne opgaven zouden worden ontvangen van alle „plantagestations”, van de producten, enz. Onnoodig hier aan te geven hoe de D. G., door den brief anders in te kleeden, zich dezen voor hem 
en voor den G.G. niet aangenamen loop der zaak had kunnen besparen.

Den 13den December 1815 (no. 3853) schreef de D. G. aan den G. G. dat volgens bericht van Z. M.'s ambassadeur aan het Hof te Londen (Fagel) van 8Dec. t. v., Z. K. H. de Prins Regent van Engeland de vereischte bevelen had gegeven om de Kol. Suriname en (zooals gezegd) de „verdere” W. I. eilanden die onder het Nederlandsche Gouvernement terugkeeren, in het bezit van Zijne Majesteit te stellen, en hoewel ik wel kan veronderstellen, dat deze bekendmaking aan $\mathrm{U}$ ten overvloede geschiedt.... (enz.).

Uit dezen brief, die den 22sten Januari naar Suriname werd gezonden, omdat zich voor dien tijd geen geschikte scheepsgelegenheid schijnt te hebben voorgedaan, en die dus te laat in de kolonie is aangekomen om den G.G. bij zijne onderhandelingen met Generaal Bonham van dienst te kunnen zijn, blijkt dat men in het Moederland niet voorzien had dat bij de teruggaaf van de Kolonie ter plaatse moeilijkheden hadden kunnen plaats vinden.

Dat Generaal Bonham van 16 Januari 1816 tot $15 \mathrm{Fe}-$ bruari d. a. v. zich tegen de teruggaaf van de kolonie verzette, hebben wij in ons aangehaald artikel aangetoond (blz. 309-316). Het is nu wel duidelijk, dat de Britsche Regeering met het geven van de vereischte bevelen aan Generaal B. tot het laatste oogenblik gewacht heeft. Waarom? Wij meenen dat de gedragslijn van de Britsche Regeering verklaarbaar kan zijn - en ook te billijken indien men zich de gebeurtenissen in Europa in 1815 indenkt en daartoe van de toen gevoerde briefwisselingen tusschen regeeringspersonen van verschillende landen kennis neemt door raadpleging van het 7de deel, Vestiging van het Koninkrijk 1813-1815, van 's Rijks Geschiedkundige Publicatiën, Gedenkstukken der Algemeene Geschiedenis van Nederland van 1795 tot 1840, in opdracht van den Minister van Binnenl. Zaken uitgegeven door Dr. H. T. Colenbrander. Men zal daarin vinden hoe een Nederlandsch Minister van Buitenlandsche Zaken zich heftig tegen het afstaan van Nederlandsche Koloniën aan Engeland verzette; hoe de Nederlandsch Gezant te Lon- 
den daarentegen een ander standpunt innam en o.a. betoogde, dat Engeland ons, die zwak en ellendig waren, op de been heeft geholpen, terwijl hij er tegen waarschuwde (Publicatiën, blz. 640; de bladzijden die wij hier citeeren betreffen het genoemde 7de deel), dat wij te hooge eischen aan Engeland zouden stellen. Hij achtte het verdriet en de gevoeligheid van Lord Castlereagh over de voortdurende klachten en pretensies van Nederlandsche zijde gegrond (P. blz. 619, 640 - 644, 844); noemde het ter zake met Engeland gesloten tractaat: „plus avantageux et „plus honorable pour ma patrie et la maison d'Orange „qu'aucun traité depuis la paix de Munster" (blz. 845) en merkte elders, zijne medewerking aan hetzelfde verdrag bedoelend op: "J'en suis très glorieux". Zooals met andere koloniën het geval was, hebben Suriname ${ }^{\mathbf{1}}$ ) evenals Curaçao (blz. 417) het lot ondergaan als „betaalmiddel” bij de gevoerde onderhandelingen in aanmerking te zijn gebracht, al is het voor beide gebiedsdeelen niet tot afstand gekomen. Engeland had de waarde van de Fransche, Nederlandsche en Deensche Koloniën in Amerika laten schatten ${ }^{2}$ ). Het werd noodzakelijk geacht aan Zweden, dat zijne aanspraken op Guadeloupe had opgegeven (blz. 615) eene vergoeding toe te kennen; aanvankelijk wilde Engeland daartoe Berbice, dan wel een millioen pond sterling, later de kolonie Suriname bestemmen ${ }^{3}$ ). Aan Holland zouden de Oostenrijksche Nederlanden worden toegevoegd - zooals ook werkelijk is geschied - en aldus zou Nederland, naar men verwachtte een van de bloeiendste en welvarendste rijken worden van Europa, doch op België rustte een Oostenrijksche schuld (blz. 733); ook Pruissen - waarmede veel moeite werd ondervonden door onwettige inbezitnemingen (blz. 718), schijnt

1) General View of the present state of the conquered W. India Colonies. Bijlage van een brief van Lord Castlereagh aan Lord Liverpool van 6 Februari 1814 (blz. 50).

2) De waarde van Suriname werd op 11.729 .000 pond sterling gesteld.

s) Brief van Lord Castlereagh aan Lord Clancarty van 30 Juli 1814 (blz. 167). Brief van den Zweedschen Minister van Buitenlandsche Zaken, Wetterstedt, aan den Zweedschen Gezant te Londen, Rehausen, van 13 Juni 1814, enz. (Blz. LII, LVII). 
nog een geldelijke vergoeding te hebben geeischt (blz. 842). Er zat aan de geldelijke regeling (Rusland was mede met een vordering verschenen wegens in 1799 verleende hulp) heel wat vast. Mogelijk heeft de Britsche Regeering, onzeker of zulk eene regeling niet alleen in theorie maar ook in de toepassing, op eene ook voor Engeland bevredigende wijze zou uitvallen, het bevel tot daadwerkelijke teruggaaf van Suriname zoo lang mogelijk uitgesteld.

De eerste brief van Gouverneur-Generaal van Panhuys uit Paramaribo, van 26 Januari 1816 (no. 1) heeft ongeveer 5 April d. a. v. den Directeur-Generaal Goldberg bereikt. Zoowel ten aanzien van een door den G. G. ingeroepen Koninklijke beslissing aangaande de uitgifte van gronden door de laatste twee Engelsche Gouverneurs, als van een verbod tegen geheime commerciëele firma's ontving hij van den D. G. ten antwoord, dat de door hem verstrekte gegevens onvoldoende waren. Ook ten aanzien van de terugkeer van slavenjongens uit Barbados (vergelijk blz. 305 van het meermalen aangehaalde artikel in de W. I. Gids) achtte de D. G. de door den G. G. verstrekte gegevens niet stellig genoeg; nopens het voorstel om onbruikbaar geworden papieren geld te verbranden luidde het antwoord weder: Uwe gegevens zijn onvoldoende (verbalen van 23 Juli 1816, nos. 4406; 3, 7, 8 en 9). Het is eigenaardig in een brief van meer dan een jaar later, van den D. G. aan den waarnemenden Gouverneur dd. 20 Augustus 1817 , no. 5953 te lezen, dat in de verbranding van het papieren geld wordt berust: het gevolg, dat men het Surinaamsche Bestuur in deze betrekkelijk onbelangrijke aangelegenheid de handen wilde binden, is dus geweest, dat dat Bestuur zelf de knoop heeft doorgehakt.

Over een voorstel, door den G. G. bij missive van $21 \mathrm{Mei}$ 1816 , no. 6 gedaan om, ten einde ingezetenen van Suriname in ,derzelver tegenwoordigen vervallen staat tegemoet te komen", de vergunning aan Noord-Amerikanen verleend, zoover uit te breiden, dat aan hen de invoer van gezouten vleesch en spek werd toegestaan, voorts om een kustvaart in te stellen naar de Fransche eilanden, naar Cay- 
enne, Para en Buenos Aires voor invoer van Fransche en Portugeesche wijnen, oliën en soortgelijke artikelen, werden (v. 7 Augustus 1816, no. 4716/10) nadere inlichtingen gevraagd. Geschiedde dit onder invloed des Konings, die gaarne alles zelf wilde regelen, die naar het verhaal luidt, over de toevallig door hem teAmsterdam waargenomen ontscheping door een Amerikaansch schip van Oostindische koffie zijn ontevredenheid betuigde? In een ander voorstel van den G. G., tot blijvende tractementsverhooging van ambtenaren, wilde de D. G. niet treden; wel beval hij duurtetoeslag aan en daarover vroeg hij 's Gouverneurs „,consideratiën..”

Aangenaam was het den D. G. te vernemen dat de G. G. (artikel, blz.305 en 306)van oordeel was, dat tengevolge van te nemen maatregelen alle uitgaven(met eenig voorbehoud) zouden kunnen worden bestreden. Maar hoezeer het Moederland voor kleeding, voor vivres van de troepen, voor de arsenalen, voor de magazijnen van oorlog en voor materialen in het hospitaal zou zorgen, zoo mocht zulks niet anders plaats hebben (deze woorden zouden voor den intusschen overleden G. G. een groote teleurstelling zijn geweest, daar zij hem de hoop op betaling door de Kolonie van alle uitgaven zouden hebben ontnomen) dan voor rekening van de Kolonie, die zou moeten ,rembourseeren”. Nieuwe belastingen zouden niet mogen worden geheven alvorens een financieel plan in het Moederland zou zijn ontvangen. (V. 20 Aug. 1816, no. 4986/1).

De schrik was echter de Nederlandsche Regeering om het hart geslagen. Hoe nu? Daar had een nieuwbenoemde Landvoogd van Suriname in uitzicht gesteld, dat de Kolonie zelve hare uitgaven zou kunnen bestrijden, mits het Moederland een op zich zelf toch niet zoo heel kostbaren steun verleende en mits men zorgde (door niet op de tractementen te beknibbelen) dat onkunde, en gebrek aan plaatselijke kennis en ondervinding op de ,pecuniëele uitgaven" geen invloed konden uitoefenen (artikel, blz. 306). Niets daarvan. Geen cent mocht de Kolonie aan het Moederland kosten. (De waarnemende Gouverneur,die eenigszins „op de proef" schijnt te hebben gediend en door den 
D. G. niet bijzonder werd gewaardeerd, schijnt zich zonder protest bij het standpunt der Regeering te hebben aangesloten; wellicht begreep hij, dat tegenover de Koninklijke lastgeving, zie verder, geen protest zou baten).

Den 7den October 1816 werd nog eens duidelijk de wil van de Ned. Regeering: Suriname mag aan het Moederland niets kosten, aan den waarnemenden Gouverneur medegedeeld. Het desbetreffende verbaal (no. 6052/2) luidt verkort :

Nader gelezen hebbende eene Missive van den GouverneurGeneraal ad interim van de Kolonie Suriname van den 10 Augustus J. L. no. 6,voorkomende bij verbaal van den 30 der gepasseerde Maand no. 5856, houdende communicatie, dat hij voor de kosten van het Transport van Mevrouw van Panhuys, dat voor den Majoor Lemmers die naar den generalen staf terugkeert en voor twee bedienden.... (enz.). - En in aanmerking nemende, dat door de uitgezonden vivres.... (enz.) in dat gedeelte der behoefte voor de troepen nagenoeg voor een geheel Jaar is voorzien.... (enz.) en dat door hetgeen verder nog voor den winter staat te worden uitgezonden, zoo in vivres als in kleedingstukken de voormelde kolonie van alles behoorlijk zal zijn verzorgd

Heeft goedgevonden en verstaan:

Aan den G. G. a. i. dienaangaande te doen afgaan de navolgende Missive.

Aan.... (enz.) .... ik vertrouw, dat door hetgeen nu werkelijk bij UWEd. Gestr. zal ontvangen zijn, de verkoop der Promessen, welke aan den Heer van Panhuys zijn medegegeven, zal kunnen zijn geëviteerd; want niets meer kan in staat zijn om 's Konings goedkeuring te erlangen, dan de verzekering dat 's Rijks Kas in het Moederland op alle mogelijke wijze worde gemenageerd.

Ook moeten de uitzendingen welke van hier gedaan worden,volgens de uitdrukkelijke begeerte van $Z$. M. niet anders dan als voorschotten aan de Kolonie worden geconsidereerd, die ter eeniger tijd zullen moeten worden gerembourseerd.

In dat Systema schreef ik dan ook bij mijn missive van den 7 September J. L. no. 10 aan den Heer Van Panhuys.... (enz). over den aankoop van meel van de Noordamerikanen, ten einde te kunnen nagaan, of het voor de Koloniale kas meer voordeelig zijn zoude, zich dat belangrijk artikel langs dien weg aan te schaffen, dan wel bij voortduring uit het Moederland te laten komen (wellicht ook voor vleesch, spek en rijst).... (enz.).

In allen gevalle (wij cursiveeren) is het de volstrekte wil van $Z$. M. 
dat de Kolonie Suriname nimmer ten laste van 's rijks kas besta, en hetzij dan dat de benoodigdheden van hier gezonden worden, hetzij dat dezelve in de Kolonie worden aangeschaft, altoos zal de Koloniale Kas voor de voldoening moeten zorgen.

UWE.G. zal het gewigt van deze stellige begeerte (id.) van Z. M. penetreeren en alzoo overtuigd zijn, dat het mij ten uitersten aangenaam zijn zal, hoogstdezelve te kunnen berichten dat hieraan stiptelijk worde voldaan.

De Staatsraad, Directeur Generaal vd.

Het komt ons voor dat hier de zuinigheid de wijsheid heeft bedrogen.

Van de brieven noemen wij nu nog slechts een van 2 September 1816, no. 5261, waarin de D. G. zoowel een moratorium, als de koersbepaling van het papieren geld weigert (artikel, blz. 305). Twee brieven met een tusschenpoos van twee dagen (17 en 19 Maart 1817, nos. 1924 en $2048 / 15)$, houden onderscheidenlijk eene goedkeuring en eene ontevredenheidsbetuiging voor $\mathrm{Mr}$. Vaillant in.

Wij vestigen er de aandacht op, dat het sedert eenige jaren mogelijk is geworden voor tijdvakken van bestuur van Surinaamsche Gouverneurs na 1816, zooals nu ten aanzien van den Gouverneur-Generaal van Panhuys is gedaan, zoowel de door de landvoogden verzonden brieven in de "Gouvernements journalen" als (daartegenover) met behulp van op het Rijksarchief aanwezige registers,de hetzelfde tijdvak betreffende ministeriëele brieven, welke thans tot en met 1850 op het Rijksarchief aanwezig zijn, op te zoeken en te raadplegen, waardoor in vele gevallen een nieuw licht op totnogtoe weinig of niet bekende gedeelten van de Surinaamsche geschiedenis zal worden geworpen en wellicht belangrijke bijdragen zullen kunnen worden samengesteld tot het verstaan van de gedachten en van de oorzaken van maatregelen in schijnbaar niet ver van ons afliggende en toch in menig opzicht nog weinig begrepen tijden. Moge dan, vrij naar het woord van Prof. Blok, deze nog aan te vatten studie in ruimen kring in Suriname aanwakkeren tot echte vaderlandsliefde, totinniger gehechtheid aan den geboortegrond en aan het maatschappelijk verband te midden waarvan men is opgegroeid. 